\title{
Optimal Generation Expansion Planning Model of a Combined Thermal-wind-PV Power System Considering Multiple Boundary Conditions: A Case Study in Xinjiang, China
}

Yu Li ( D1034095642@163.com)

Mei Dai

North China Electric Power University

Songtao Hao

State Grid Corporation of China

Gang Qiu

State Grid Corporation of China

Guoqing Li

State Grid Corporation of China

Guilian Xiao

State Grid Corporation of China

Dagui Liu

State Grid Corporation of China

Original article

Keywords: Optimization Model, Generation Expansion Planning $₫ \mathrm{GEP} \otimes$, Multiple Boundary Conditions, Renewable Energy

Posted Date: May 10th, 2020

DOl: https://doi.org/10.21203/rs.3.rs-22631/v1

License: (c) (1) This work is licensed under a Creative Commons Attribution 4.0 International License. Read Full License

Version of Record: A version of this preprint was published at Energy Reports on November 1st, 2021. See the published version at https://doi.org/10.1016/j.egyr.2021.01.020. 
1 Optimal Generation Expansion Planning Model of a Combined

2 Thermal-wind-PV Power System Considering Multiple Boundary

3 Conditions: A Case Study in Xinjiang, China

4

\author{
$\mathrm{Yu} \mathrm{Li}^{1 *}$, Mei Dai ${ }^{2}$, Songtao Hao ${ }^{1}$, Gang $\mathrm{Qiu}^{1}$, Guoqing $\mathrm{Li}^{1}$, Guilian Xiao ${ }^{1}$, Dagui Liu ${ }^{1}$
}

* Correspondence: D1034095642@163.com; 'State Grid Xinjiang Electric Power Co., Ltd., Urumqi 830000,

China; ${ }^{2}$ School of Economics and Management, North China Electric Power University, Beijing 102206, China

\title{
Abstract
}

Background: The scarcity of fossil fuels and their high emissions impact on the environment have forced the rapid development of renewable energy. Wind and photovoltaic power play a more and more important role in today's power system because of their clean and renewable characteristics. However, with the large-scale grid connection of wind and photovoltaic power, the contradiction between renewable energy and thermal power is becoming more and more serious. The unreasonable planning of power generation resources has also caused a lot of waste of electric power. Methods: To solve this problem, this paper comprehensively considers the construction and operation costs of power plants, and constructs an optimal generation expansion planning model of a combined thermal-wind-PV power system with the objective of minimizing total cost. The planning is calculated under the boundary conditions of ensuring the safe operation of the power grid and taking into account the share requirement, utilization requirements and construction requirements for renewable energy. The model is applied to the self-use and external power plants in Xinjiang.

Results: The results show that this generation expansion plan can reduce the total cost of the power plants while ensuring the load demand. The renewable energy has also received more consumption share and its abandonment rate has dropped significantly. Numerical examples show that the optimization model has good applicability.

Conclusion: The proposed optimization model can realize the coordinated development of three types of power sources under multiple boundary conditions, which can not only guarantee the economy of power construction, but also take into account the optimization of environmental benefits. Reasonable generation expansion planning can improve energy efficiency, achieve clean and low carbon in the process of power generation, and promote the sustainable development of society.

Keywords: Optimization Model; Generation Expansion Planning (GEP) ; Multiple Boundary Conditions; Renewable Energy 


\section{Background}

The energy and power industry is an important support for the rapid development of the national economy [1]. With the rapid consumption of fossil fuels in the past, it has not only caused the global energy crisis, but also aggravated the environmental problems [2]. Therefore, clean and renewable energy, represented by wind and PV power, has gradually gained attention [3]. Many countries have taken positive measures to increase the installed capacity of renewable energy [4-6]. China has also promulgated a number of policies to promote the development of renewable energy [79]. As of 2018, China's renewable energy installed capacity reached $728 \mathrm{GW}$, accounting for about $32 \%$ of the world. The installed capacity of hydropower, wind and PV power reached 352, 185 and 175GW respectively, ranking first in the world [10]. However, the excess installed capacity has brought about a serious situation of renewable energy abandonment. According to the National Energy Administration, the national abandoned amount of hydropower, wind and PV power reached 69, 28 and 5TWh respectively in 2018 [11]. In provinces with more renewable energy installed capacity, such as Xinjiang and Gansu, the abandonment rate even exceeds 20\% [12]. Therefore, how to properly plan the development of renewable energy has become the main problem at present.

China's electricity demand and supply are inversely distributed. The load centers are mainly concentrated in the central and eastern regions, while the power supply centers are mainly concentrated in the northwest [13]. To solve this problem, China has implemented the West-East Power Transmission Strategy and built several UHV transmission channels [14]. As a major energy province in China, Xinjiang undertakes an important responsibility and its power supply and power grid are in a critical period of large-scale construction and leaping development. With its own resource advantages and policy support, Xinjiang's power industry has made considerable progress. By the end of 2018, the total installed capacity of power supplies in Xinjiang was 86GW, including wind power of $19 \mathrm{GW}$ and PV power of $10 \mathrm{GW}$ [15]. However, the large installed capacity of renewable energy has also brought a lot of problems to the Xinjiang power grid. On the one hand, due to the self-use demand has not been deeply excavated and the external transmission space has not been effectively developed, there is a serious phenomenon of renewable energy abandonment in Xinjiang. The high spillage rate has caused Xinjiang to be included in the red warning zone of developing renewable energy for three consecutive years, suspending the construction of wind and 
PV power [16,17]. On the other hand, in order to solve environmental problems and 71 promote clean energy development, China has issued a series of policies to promote priority dispatch of renewable energy [18]. These one-size-fits-all policies has made even if there is a waste of renewable energy in Xinjiang, its thermal power has not received a corresponding share of power generation, which makes it more difficult to distribute load demand that is already insufficient. The economic interest conflict between thermal power and renewable energy is becoming increasingly serious. In addition, the randomness and volatility of wind and PV power pose great challenges to the security and stability of Xinjian's power grid. How to satisfy the interests of thermal, wind and PV power plants under the premise of ensuring the safe operation of the power grid is of great significance to the coordinated development of various types of power sources in Xinjiang.

Optimizing the structure of the power system involves a lot of funds and resources. The GEP model is a good way to solve this kind of problem, which can choose the best energy distribution at an acceptable economic cost [19-21]. The GEP model can be divided into three categories: optimization models, general/partial equilibrium models and alternative models, but the optimization model is the most widely used [22]. S.Y. Chen et al. proposed a multi-regional power GEP model considering air pollutants emission constraints [23]. He applied the model to China and found that replacing large coal-fired power plants with renewable power sources can well reduce pollutant emissions. Chen et al. analyzed the impact of the non-carbon external cost of different power generating technologies on China's power planning [24]. M.D. Rodgers et al. introduced the damage caused by the power industry to human health into the GEP and constructed the optimization model with the objective of minimizing social costs [25]. I. Khan. analyzed the feasibility and sustainability of the GEP from the social, environmental and economic aspects and he pointed out that the design of energy policies must strike a balance between all three aspects [26]. With the massive integration of renewable energy resources, the formulation of GEP has become more and more complicated [27-29]. J. English et al. applied short-term constraints to the

99 long-term GEP model to deal with the increasing demand for power system flexibility 100 caused by the large-scale penetrations of renewable energy [30]. Based on an analysis 101 of the current situation of Spain's power system, R. Gómez-Calvet et al. used the Linear 102 Programming Optimization Technique (LPOT) to optimized the mix of renewable energy to reduce the need of reserve capacity and surplus power [31]. B. Canizes et al. 
constructed a two-stage GEP model considering the effects of seasonal and daily periods impact on renewable energy and the optimization scheme achieves the lowest cost and line loss at the same time [32]. D. Quiroga et al. set up five scenarios that represent different trends and energy policies over the next decade, and on this basis studied the impact of pollutant emission policies GEP. The results shown that the availability of renewable energy may improve the effectiveness of emission policies [33]. S. Pineda et al. proposed a GEP model that included both electricity and certificate markets to analyze the impact of quotas and penalty costs on the capacity expansion of renewable energy generation, and found that the introduction of the markets reduced its installed capacity [34].

Although the above papers have studied GEP models from multiple aspects, they mostly focus on the dispatching side or the user side. These papers set the main optimization goal to minimize the cost of power construction or minimize environmental pollution, while ignoring the economics of the power plants. Of course, the method they proposed cannot be applied well to Xinjiang's complex power background. Therefore, based on the current power operation status in Xinjiang, this paper constructed an optimal GEP model of a combined thermal-wind-PV power system considering multiple boundary conditions from the power supply side. First of all, this paper analyzed the income and expenditure of the thermal, wind and PV power plants in Xinjiang, and calculated their break-even hours. Then, according to the various national policies for the development of renewable energy resources, three boundary conditions were set up: share requirements, utilization requirements and construction requirements. Finally, under these conditions, the optimal GEP of thermal, wind and PV power plants in Xinjiang in from 2020 to 2030 was designed based on the self-use and external load demand, which could provide reasonable suggestions for the coordinated development of various power resources in Xinjiang during the "14th FiveYear Plan" and the "15th Five-Year Plan".

The rest of the paper is organized as follows. Section 2 states the presuppositions for developing the GEP model, and details its objective function and constraints, as well as the three boundary conditions. Section 3 introduces the operating status of Xinjiang power supply and the related data in the model. The optimal GEP is analyzed and discussed in Section 4, and Section 5 provides a summary and concluding remarks.

\section{Model and Methods}

\subsection{Presupposition}


The construction of the planning model needs to consider a variety of influencing

139 factors. In order to improve the applicability of the model, this paper proposes the

140 following assumptions combined with the energy development status of Xinjiang.

(1) The fuel of thermal power only consider coal and the unit does not carry out major technical upgrading during the planning period, so the coal consumption coefficient will not drop significantly;

(2) The cost of the thermal power unit includes fuel cost and operation cost excluding coal transportation costs, and the remaining renewable power units only include operation cost;

(3) The break-even utilization hours will be affected by the income and expenditure costs for the individual power generation units. Therefore, this paper selects the average break-even utilization hours of each types of power sources in Xinjiang for calculation;

151 (4) Because the self-use and external power supply cannot be used interchangeably, 152 it needs to be separately constrained;

153 (5) The construction of UHV transmission channels needs to be considered from multiple aspects. In the case that there is no new UHV line put into operation in the future, the capacity of the supporting power supply will not be increased during the planning period.

Based on the above assumption, the generation planning model is constructed with the minimum total investment and operating cost as the optimization goal.

\subsection{Generation expansion planning model}

\subsubsection{Objective function}

In the power planning, the main consideration is the investment cost of the new power plants, as well as the operation cost of the generators. Therefore, the optimization goal is to minimize the total cost.

$$
\begin{gathered}
\text { MinZ }=C+C^{*}(1) \\
C=\sum_{t=1}^{T} \sum_{i=1}^{N} \Delta Q_{i, t} P_{i, t}+\sum_{t=1}^{T} \sum_{i=1}^{N} H_{i, t} Q_{i, t} \delta_{i, t} \\
C^{*}=\sum_{t=1}^{T} \sum_{i=1}^{N} \Delta Q_{i, t}^{*} P_{i, t}^{*}+\sum_{t=1}^{T} \sum_{i=1}^{N} H_{i, t}^{*} Q_{i, t}^{*} \delta_{i, t}^{*}
\end{gathered}
$$

\subsubsection{Constraints}

(1) Power balance constraint 
real time [35].

$$
(1-\lambda) \sum_{i=1}^{N} H_{i, t} Q_{i, t}\left(1-\theta_{\text {loss }}\right)=G_{t}
$$

$$
\lambda \sum_{i=1}^{N} H_{i, t}^{*} Q_{i, t}^{*}\left(1-\theta_{\text {loss }}^{*}\right)=G_{t}^{*}
$$

171

\section{(2) Reserve capacity constraint}

In order to achieve stable operation of the power system, it is necessary to select a power supply unit with adjustment capability for peak shaving to cope with random changes in load. In this paper, thermal power is selected as the peaking unit, and it should be able to provide a certain reserve capacity [36].

$$
\begin{aligned}
& Q_{1, t} \geq \eta A_{t} \\
& Q_{1, t}^{*} \geq \eta^{*} A_{t}^{*}
\end{aligned}
$$

\section{(3) Power generation economic constraint}

In order to ensure the economic benefits of power plants, the utilization hours should not be lower than the average break-even utilization hours, but not higher than the theoretical utilization hours.

$$
\begin{aligned}
& S_{i} \leq H_{i, t} \leq H_{i, \text { max }} \\
& S_{i}^{*} \leq H_{i, t}^{*} \leq H_{i, \text { max }}^{*}
\end{aligned}
$$

(4) Renewable energy utilization constraints

According to the relevant national policy, the minimum utilization rate of renewable energy should be constraint.

$$
\frac{H_{i, t}}{H_{i, \max }} \geq \alpha_{i, t}, i=2,3
$$

$$
\frac{H_{i, t}^{*}}{H_{i, \max }^{*}} \geq \alpha_{i, t}^{*}, i=2,3
$$

(5) Construction capacity constraint

Due to the overcapacity of Xinjiang's renewable energy, it is necessary to improve the utilization rate of the unit before increasing new capacity.

$$
\begin{aligned}
& \Delta Q_{i, t}=\left\{\begin{array}{l}
Q_{i, t}-Q_{i, t-1}, \frac{H_{i, t-1}}{H_{i, \max }} \geq \beta_{i, t-1} \\
0, \frac{H_{i, t-1}}{H_{i, \max }}<\beta_{i, t-1}
\end{array}\right. \\
& \Delta Q_{i, t} \geq 0
\end{aligned}
$$


(6) Renewable energy penetration constraint

Renewable energy power generation is greatly affected by natural resources. The characteristics of random intermittent output pose challenges to the stable operation of the power grid. Therefore, it is necessary to constrain the maximum penetration rate of wind and PV power [37].

$$
\begin{aligned}
& \vartheta G_{t} \leq \sum_{i=2}^{N} H_{i, t} Q_{i, t}\left(1-\theta_{\text {loss }}\right) \leq \gamma_{t} G_{t} \\
& \vartheta_{t}^{*} G_{t}^{*} \leq \sum_{i=2}^{N} H_{i, t}^{*} Q_{i, t}^{*}\left(1-\theta_{\text {loss }}^{*}\right) \leq \gamma_{t}^{*} G_{t}^{*}
\end{aligned}
$$

\subsection{Multiple boundary conditions}

\subsubsection{Share requirements for non-hydropower renewable energy}

According to the Notice on Establishing and Improving the Safeguard Mechanism for Renewable Energy Power Consumption, renewable energy power consumption responsibility weights are set by the province's power consumption. The requirements for Xinjiang from 2018 to 2020 are $11.5 \%, 12 \%$ and 13\%, respectively. However, since this paper only considers three types of power resources, the weights of nonhydropower renewable energy in 2020,2025 , and 2030 are set to $30 \%, 35 \%$, and $40 \%$, respectively.

\subsubsection{Utilization requirements for renewable energy}

According to the Clean Energy Dissipation Action Plan (2018-2020), it is necessary to optimize the power structure, reasonably control the pace of power development, and improve the utilization rate of power supply during the 13th fiveyear Plan period. The target for clean energy consumption in Xinjiang is that the utilization rate of PV power should reach $85 \%$ in 2018, 90\% in 2019 and 2020, and wind power utilization rates should reach $75 \%, 80 \%$ and $85 \%$ in 2018, 2019 and 2020 respectively. With the increasingly serious problems of energy and environment, the requirements for energy efficiency will become stricter. Therefore, the utilization rate of wind and PV power is set to $95 \%$ and $90 \%$ respectively in 2025 , and it will reach to $95 \%$ in 2030 in this paper.

\subsubsection{Construction requirements for renewable energy}

According to the Notice on Establishing Monitoring and Early Warning Mechanism to Promote Sustainable and Healthy Development of Wind Power Industry 
and Notice on Establishing a Market Environment Monitoring and Evaluation

220 Mechanism to Guide the Healthy and Orderly Development of the Photovoltaic 221 Industry, Xinjiang has been in the red warning zone for three years, and it is not allowed

222 to increase the installed capacity of renewable energy. Since the red warning requires multiple indicators to judge, in order to simplify the calculation, this paper sets the wind and PV abandonment rates are less than $15 \%$ and $10 \%$ respectively as the red warning release standard.

\section{Application}

\subsection{Problem statement}

In recent years, due to the energy red warning, the growth rate of renewable energy installed capacity in Xinjiang has slowed down, and the proportion of renewable energy decreased slightly. Although the power supply structure is constantly being optimized,

232 has squeezed the share of thermal power, making the profitability of various power generation resources different. The contradiction of interest between renewable energy and thermal power has intensified. On the other hand, subject to load demand, the abandonment of wind and PV caused by excessive installed capacity still exists.

236 Therefore, the current principle of power supply construction in Xinjiang is to promote coordinated and orderly development of all kinds of power sources under the condition of ensuring the safety and stability of power system. Specifically, it is necessary to avoid disorderly competition and prevent redundant construction. While optimizing the

240 development of thermal power and improving energy efficiency, renewable energy

241 sources represented by wind and PV power should be actively developed to reduce

242 environmental pollution, thereby achieving efficient, clean, low-carbon power supply.

\section{$243 \quad 3.2$ Data}

\section{$244 \quad$ 3.2.1 Break-even hours}

245 Under the current average on-grid price level, the break-even hours are calculated 246 according to the cost and benefit data of the power plants (Table 1).

Table 1 The current break-even hours of three power recourses

\begin{tabular}{rrr}
\hline Thermal power & Wind power & PV power \\
\hline
\end{tabular}

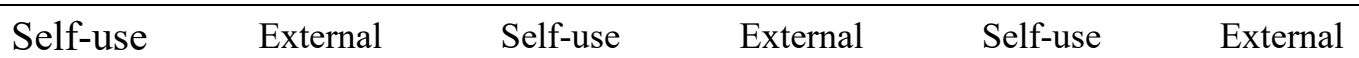


During the planning period, the coal price is on the rise and the on-grid price of renewable energy will fall because of the new electricity price policy, which would reduce the income of three kinds of power plants resulting an increase in their breakeven hours (Table2).

Table 2 Break-even hours under multiple boundary conditions

\begin{tabular}{cccccc}
\hline \multicolumn{2}{c}{ Thermal power } & \multicolumn{2}{c}{ Wind power } & \multicolumn{2}{c}{ PV power } \\
\hline Self-use & External & Self-use & External & Self-use & External \\
4779 & 2507 & 1755 & 1789 & 1246 & 1314 \\
\hline
\end{tabular}

\subsubsection{Self-use demand}

In recent years, the self-use demand in Xinjiang has been increasing, but the growth rate has shown a downward trend. The average annual growth rate from 2015 to 2018 was $13.84 \%$ and the largest rate occurred in 2017 at $21.30 \%$. After the rapid increase in demand, it has become relatively saturated. It is expected that the self-use demand in Xinjiang will reach 129, 190 and 270 TWh by 2020, 2025 and 2030 respectively. The five-year average growth rate is $10.36 \%, 8.14 \%, 7.28 \%$. The growth trend of self-use demand in Xinjiang is shown in Fig.1.

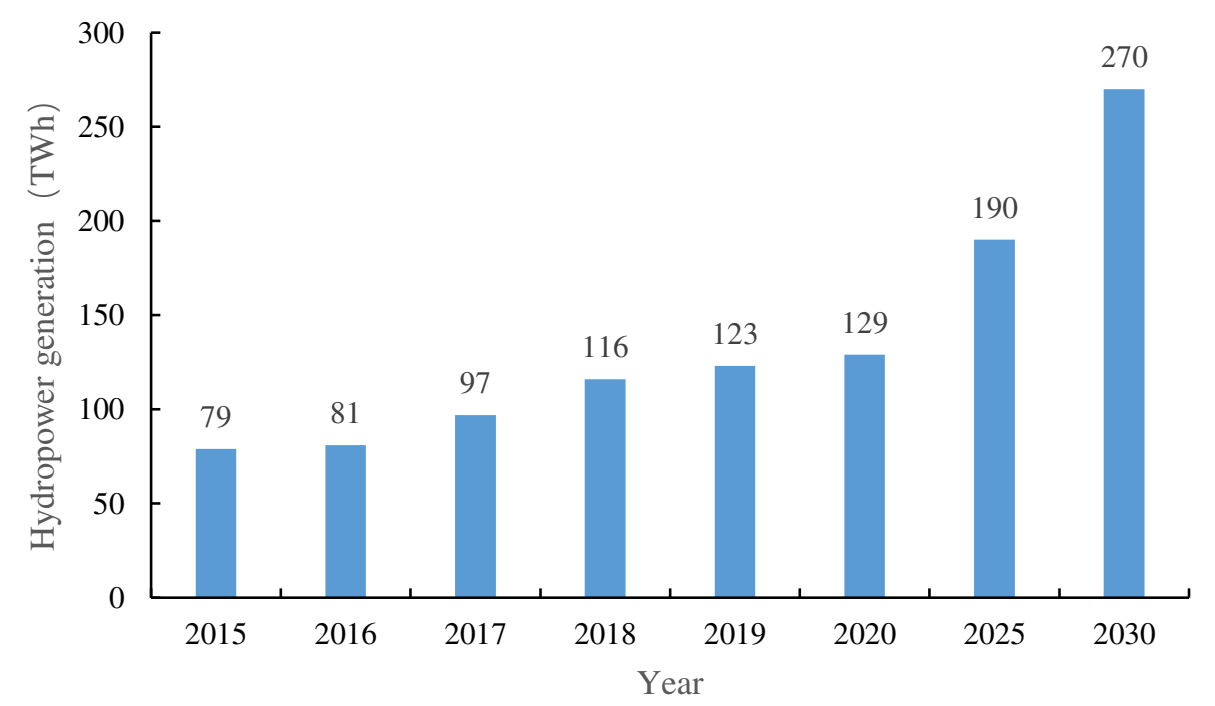

Figure 1 Self-use demand in Xinjiang during the planning period

Since this paper does not consider the hydropower generation, it must be deducted 264 from the above self-use demand, and the rest is the total power generation of thermal, 265 wind and PV power in Xinjiang. Affected by water flow, the change of hydropower generation is relatively stable. It is estimated that hydropower generation will increase 
by 4.5 TWh per year from 2020 to 2025 , and continue to grow at 4 TWh per year from 2682026 to 2030. The growth trend of hydropower generation is shown in Fig.2 and the total generation amount of thermal, wind and PV power during the planning period is 270 shown in Fig.3.

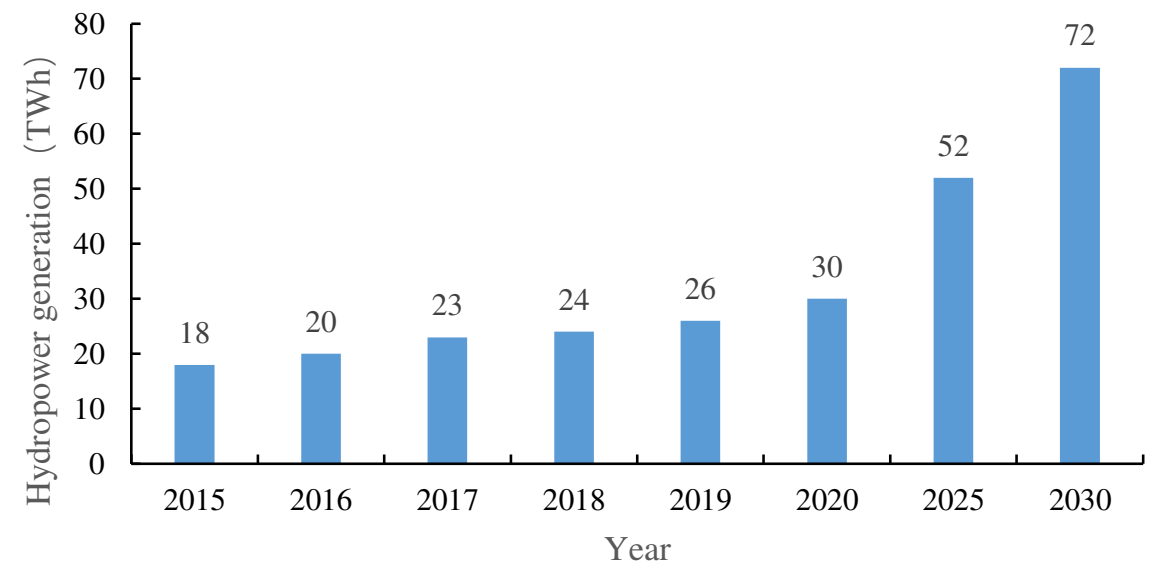

Figure 2 Hydropower generation amount during the planning period

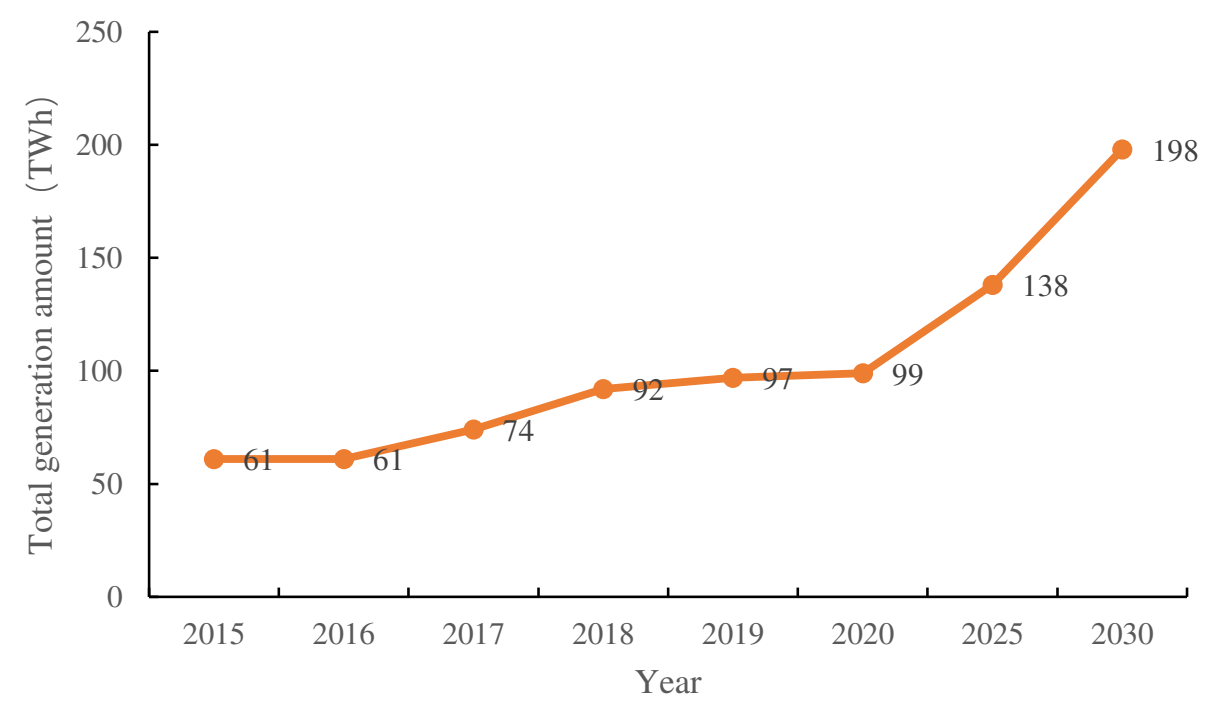

Figure 3 Total generation amount of three power resources

\subsubsection{External demand}

276 The demand for external power transmission is mainly related to the receiving end. 277 According to the actual electricity consumption in 2015-2018, the external power 278 demand is expected to increase by 12 TWh per year from 2020 to 2025 and continue to 279 grow at $8 \mathrm{TWh}$ per year from 2026 to 2030 . The growth trend of external power demand 280 is shown in Fig.4. 


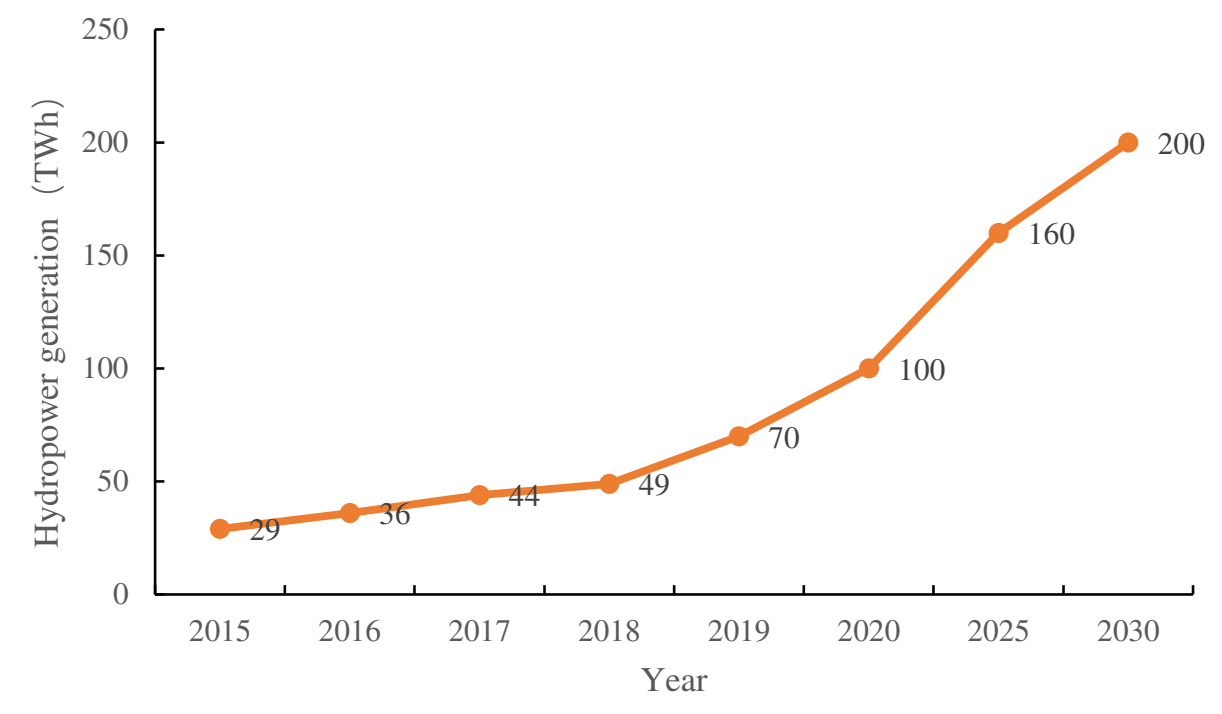

\section{Result and discussion}

\subsection{Generation expansion analysis}

The existing installed capacity can achieve the break-even of the three types of power supply in the case of meeting the power load and various policies in 2020. By 2025 , in order to meet the increasing demand, compared with 2020, it needs to increase the thermal power of $6 \mathrm{GW}$, wind power of $9 \mathrm{GW}$, and PV power of $7.5 \mathrm{GW}$. And by 2030, with the further increase of the self-use and external load demand, it needs to increase thermal power by $3 \mathrm{GW}$, wind power by $13 \mathrm{GW}$ and photovoltaic by $14.5 \mathrm{GW}$, compared with 2025 .

As can be seen from the Table 3, with the increase in the self-use and external demand of Xinjiang, the three types of power operation hours are higher than the breakeven hours, which can obtain a certain profit. However, the utilization hours of the supporting thermal power in 2020 are low. This is because in the case of insufficient total load demand in Xinjiang, the self-use thermal power can only increase revenue by seizing the share of external thermal power in the UHV transmission channel to achieve profitability. And since the break-even utilization hours of the supporting thermal power plants are relatively low, they can still make a profit after dividing part of the grid share to the self-use thermal power plants. This phenomenon will be alleviated as the total demand increases. Although the power delivery ratio is gradually increasing, this is due to the fact that there is no increasing in the UHV supporting power plants and make more full use of the self-use power plants. Although the total investment operating cost is gradually rising due to the construction cost caused by the new installed capacity, the 
growth rate is slowing down, which is because the gradual saturation of the power supply and the reduction in unit cost.

Table 3 Optimal capacity results of thermal, wind and PV power in Xinjiang

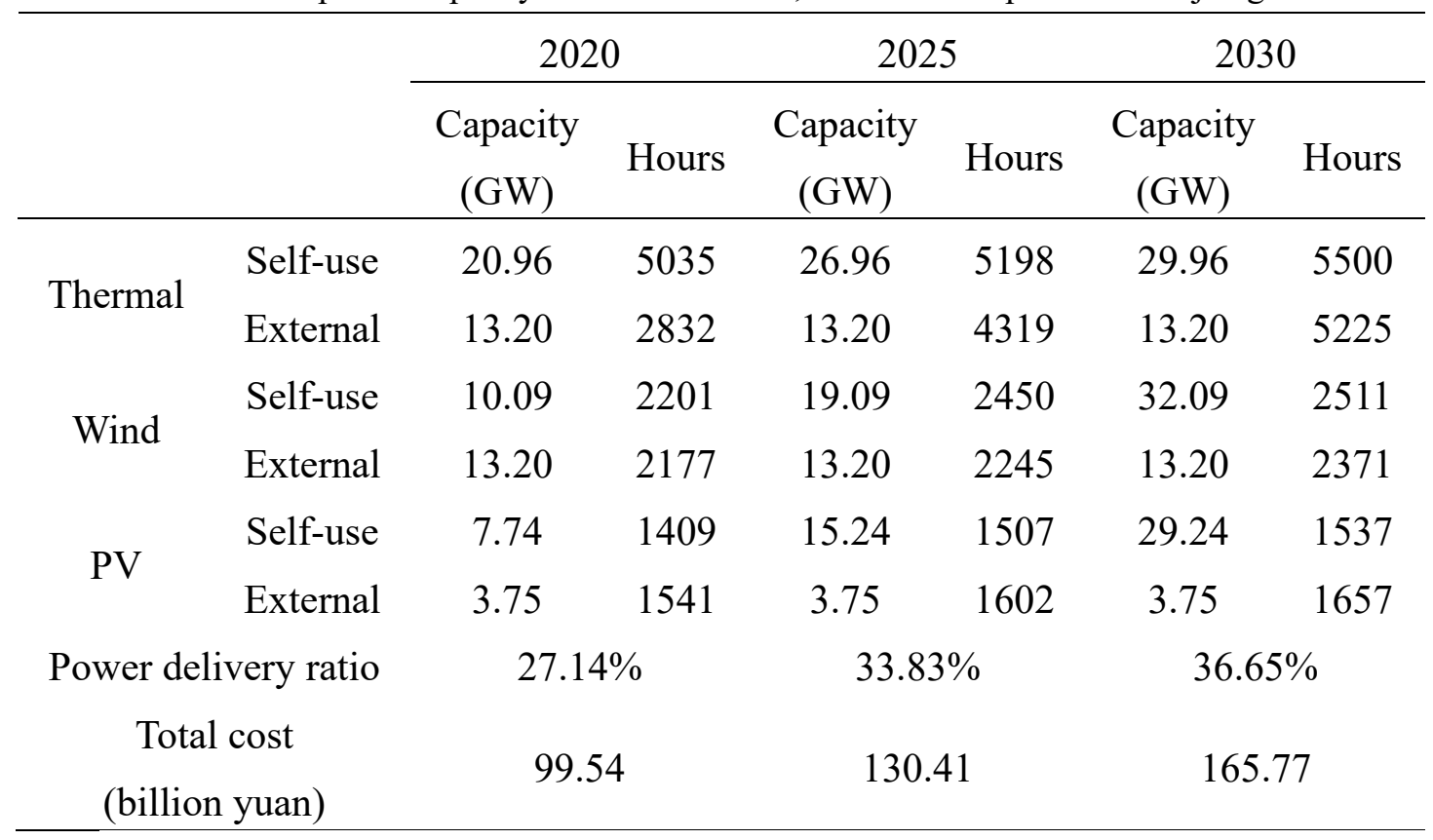

Under the optimized generation expansion plan, the operation hour of thermal, wind and PV power plants are high, which can realize the break-even of three kinds of power sources under the condition of coal price fluctuation. The generation planning model has good applicability.

\subsection{Renewable energy efficiency analysis}

313 As clean and low-carbon renewable energy, the utilization efficiency of wind and 314 PV power is also a key factor in generation expansion planning. Fig. 5 shows the 315 utilization rate of Xinjiang's renewable energy during the planning period. Influenced 316 by policies and social responsibilities, the utilization rate of renewable energy is 317 increasing year by year, and the development trend is unchangeable. The utilization 318 rate of wind power has gradually increased from $85.85 \%$ to $96.42 \%$, and that of PV 319 power is even close to $98 \%$. This may be caused by the following two reasons. On the 320 other hand, the power structure in Xinjiang is also gradually optimized to clean and low 321 carbon. As can be seen from Fig 6, the proportion of thermal power installation has 322 remained below 50\% and decreased year by year. While the renewable energy 323 penetration rate is increasing and reached over $41.23 \%$ in 2030 , which is far higher 324 than the requirement of national policy. 


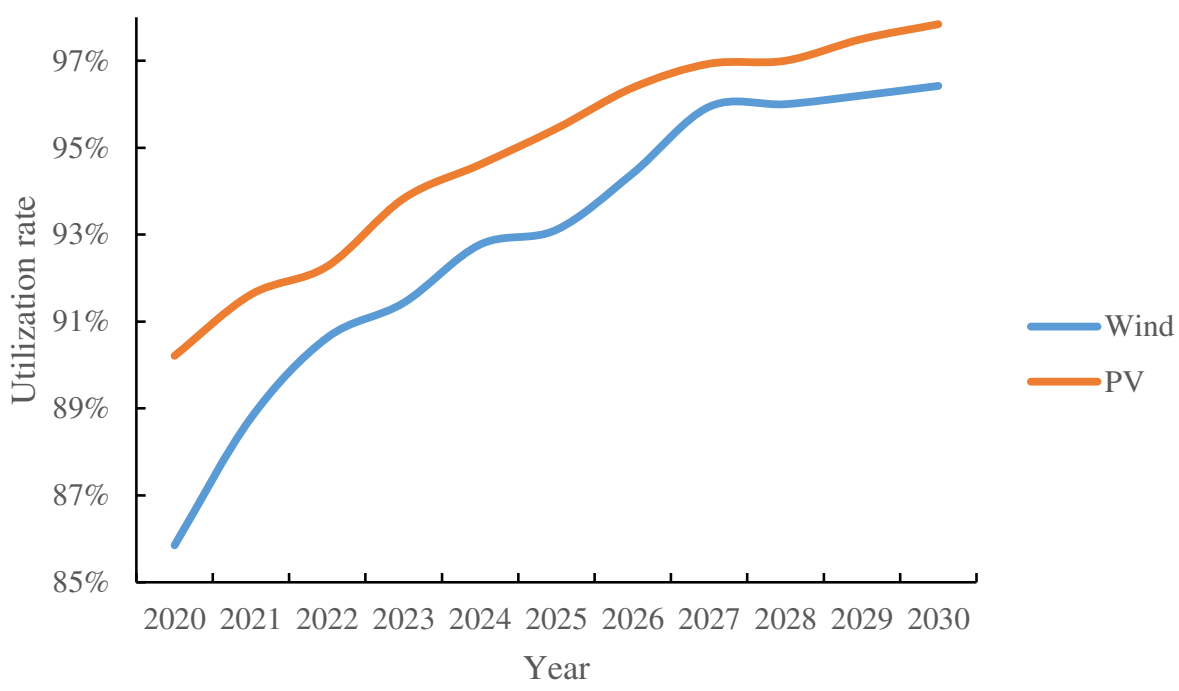

Figure 5 Utilization rate of renewable from 2020 to 2030

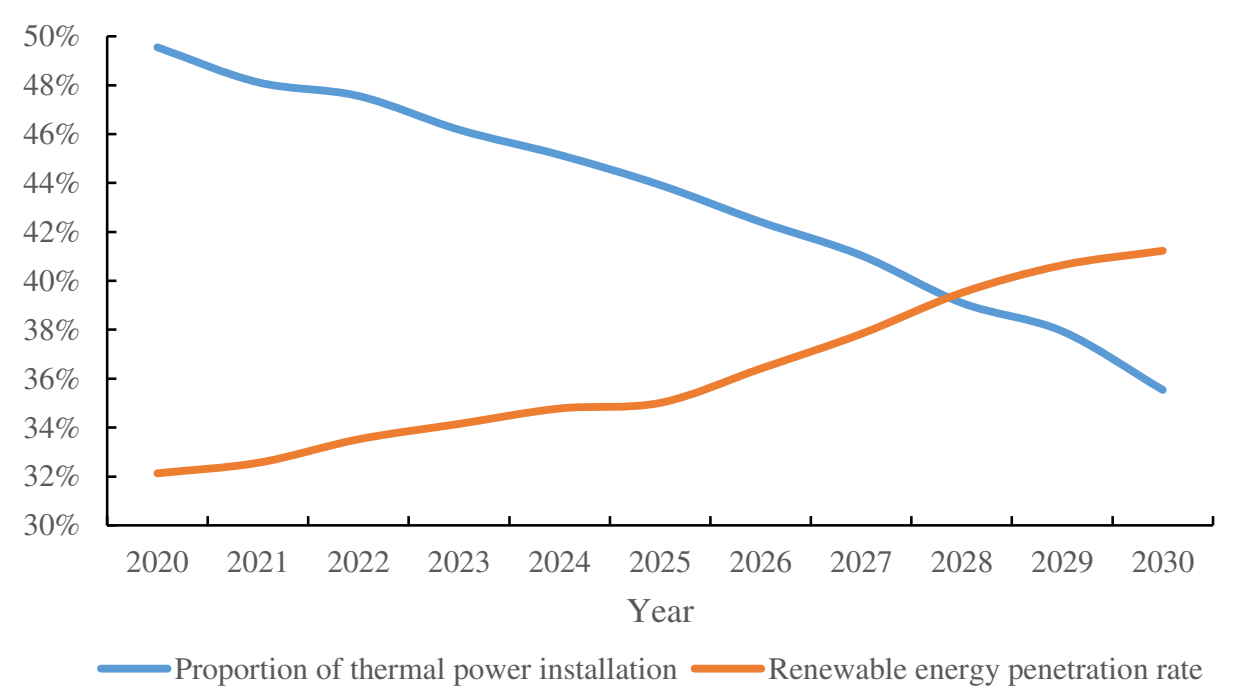

\subsection{Sensitivity analysis}

330 Total load demand is the decisive factor affecting the installed capacity. Therefore,

331 based on the above plan, the influence of self-use and external demand changes on the

332 optimization model is analyzed. The change rate is set to $\pm 5 \%$ and the results are shown

333 in Fig. 7. Thermal power is the most sensitive to total demand changes, followed by

334 wind power, and PV power is the least sensitive. On the one hand, due to the limitation

335 of renewable energy penetration, wind and PV power can't be installed in large

336 quantities. The grid connection of renewable energy requires the power system to

337 provide spare capacity, which will also increase the installed capacity of thermal power. 
On the other hand, because of the high break-even hours of thermal power plants, it accounts for the most power generation amount in the case of the same installed growth in order to meet the economic benefits of all kinds of power resources.

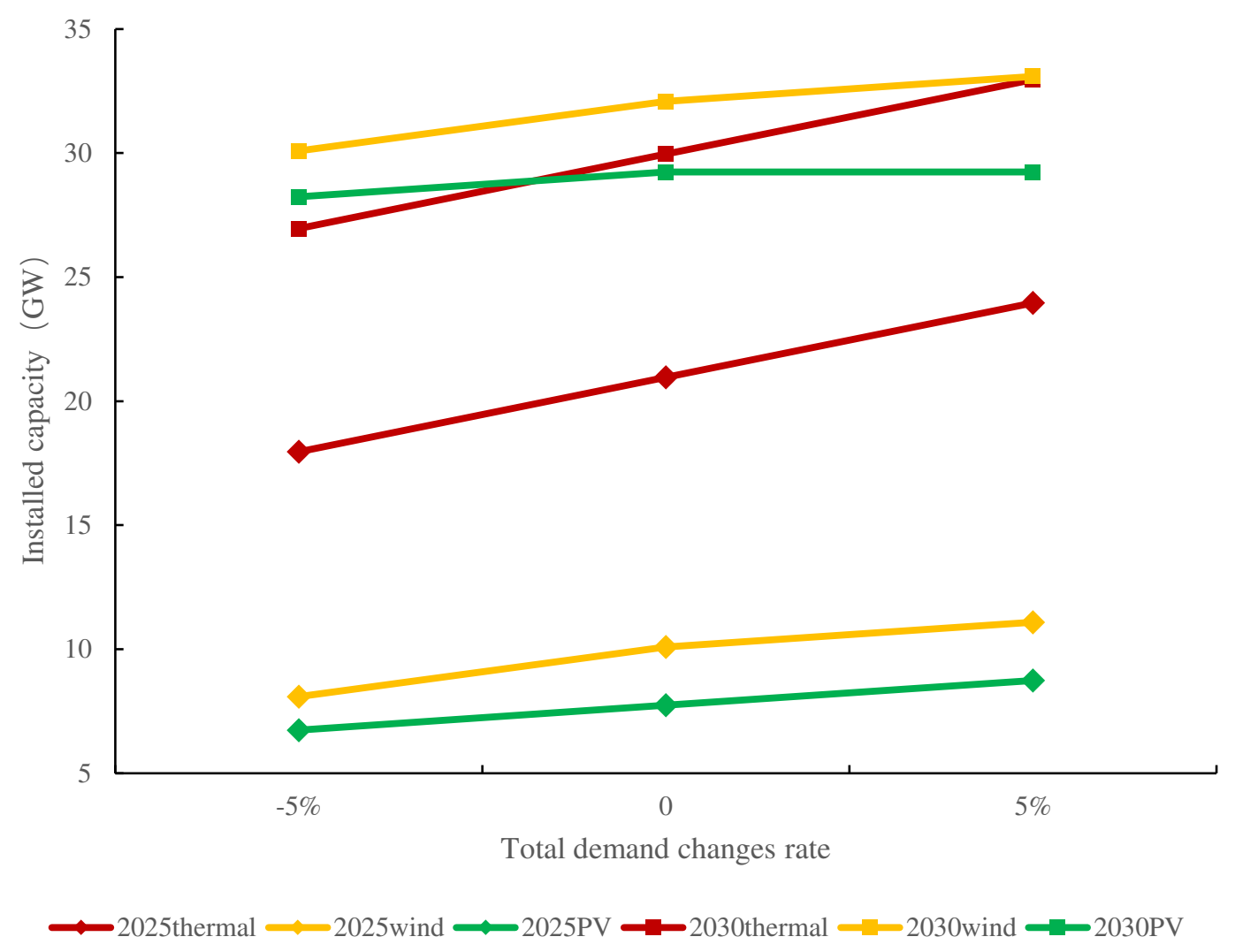

Figure 7 Sensitivity analysis result of optimization model (excluded the external power plants)

\section{Conclusion}

In order to realize the coordinated development of power supply, this paper studies the optimal configuration of Xinjiang's thermal, wind and PV power capacity from 2020 to 2030 based on the operating status of power plants. Firstly, the self-use and external demand in Xinjiang and hydropower generation amount are estimated, thus obtaining the development space of thermal, wind and PV power supply. Then, the break-even utilization hours are calculated according to the power plants' cost and income data obtained from field research. Finally, with the objective of minimizing the total investment and operating cost, the optimal generation planning model of thermal, wind and PV power plant is constructed and solved under multiple boundary conditions. The results show that there is a certain redundancy in the existing installed capacity in Xinjiang, which can achieve the break-even of the three types of power supply in the case of meeting the power load and various policies in 2020. Affected by national policies and the economic advantages of renewable energy, the generation expansion 
357 rate of wind and PV power is higher than that of thermal power. The profitability of the 358 UHV supporting power supply is higher than that of the self-use power plants. 359 Therefore, the proper development of the UHV transmission channels will help 360 improve the economics of power generation. The generation planning model proposed 361 in this paper can help to realize the optimal allocation of thermal, wind and PV power 362 in Xinjiang. The proposed plan can improve the penetration rate and utilization rate of 363 renewable energy and meet the economic demands of the three types of power sources 364 in the context of the gradually stringent national environmental protection policy. 
367 GEP: Generation Expansion Planning; PV: Photovoltaic

\begin{tabular}{|c|c|}
\hline \multicolumn{2}{|r|}{ Nomenclature } \\
\hline \multicolumn{2}{|c|}{ Subscripts and decision variables } \\
\hline$t$ & Time period, $\mathrm{t}=2020-2030$ \\
\hline$i$ & $\begin{array}{l}\text { Type of power-generation facilities, } i=1-3 \text {; coal-fired power, wind power, } \\
\text { and photovoltaic power }\end{array}$ \\
\hline$C / C^{*}$ & Total investment and operating cost of self-use/external power unit \\
\hline$H_{i, t} / H_{i, t}^{*}$ & $\begin{array}{l}\text { Generating equipment availability hours of self-use/external power unit } i \\
\text { in period } t\end{array}$ \\
\hline$Q_{i, t} / Q_{i, t}^{*}$ & Installed capacity of self-use/external power unit $i$ in period $t$ \\
\hline$\Delta Q_{i, t} / \Delta Q_{i, t}^{*}$ & Newly installed capacity of self-use/external power unit $i$ in period $t$ \\
\hline \multicolumn{2}{|l|}{ Parameters } \\
\hline$A_{t} / A_{t}^{*}$ & Average self-use/external load in period $t$ \\
\hline$G_{t} / G_{t}^{*}$ & Total self-use/external demand in period $t$ \\
\hline$H_{i, \max } / H_{i, \max }^{*}$ & Theoretical utilization hours of self-use/external power unit $i$ \\
\hline$P_{i, t} / P_{i, t}^{*}$ & Installation cost of self-use/external power unit $i$ in period $t$ \\
\hline$S_{i} / S_{i}^{*}$ & Break-even utilization hours of self-use/external power unit $i$ \\
\hline$\alpha_{i, t} / \alpha_{i, t}^{*}$ & Minimum utilization rate of self-use/external power unit $i$ in period $t$ \\
\hline$\beta_{i, t} / \beta_{i, t}^{*}$ & $\begin{array}{l}\text { Utilization rate of self-use/external power unit } i \text { in period } t \text { for adding } \\
\text { new power plants }\end{array}$ \\
\hline$\gamma_{t} / \gamma_{t}^{*}$ & Maximum penetration rate of self-use/external power unit $i$ in period $t$ \\
\hline$\theta_{\text {loss }} / \theta_{\text {loss }}^{*}$ & Comprehensive line loss rate of self-use/external transmission channels \\
\hline$\lambda$ & Power delivery ratio \\
\hline$\eta / \eta^{*}$ & Reserve capacity coefficient of self-use/external thermal power \\
\hline$\delta_{i, t} / \delta_{i, t}^{*}$ & Operating cost of self-use/external power unit $i$ in period $t$ \\
\hline$\vartheta / \vartheta_{t}^{*}$ & Non-hydropower renewable energy weights in period $t$ \\
\hline
\end{tabular}

\section{Declarations}

\section{Ethics Approval and Consent to Participate}

372 Not applicable.

\section{Consent for publication}

375 Not applicable.

378 The datasets used and analysed during the current study are available from the corresponding author 
on reasonable request.

\section{Competing interests}

382 The authors declare that they have no competing interests.

\section{Funding}

This research is supported by the science and technology project of State Grid Xinjiang Electric Power Co., Ltd. (SGXJ0000TKJS1900287).

\section{Authors' contributions}

389 LY contributed to the design of the work, acquisition of data, analysis and interpretation of data,

390 drafting of the work, and management work. DM contributed to the design of the work, acquisition 391 of data, analysis and interpretation of data, drafting of the work, and management work. HST and 392 LDG contributed to the design of the work, interpretation of data, and drafting of the work. QG 393 contributed to the design of the work, interpretation of data, and drafting of the work. LGQ and 394 XGL have contributed equally to the writing and contributed to the revising and finalizing of the 395 article. The authors read and approved the final manuscript.

\section{Acknowledgements}

398 The authors are grateful to the editors and the anonymous reviewers for their insightful comments 399 and suggestions.

\section{Authors' information}

$402{ }^{1}$ State Grid Xinjiang Electric Power Co., Ltd., Urumqi 830000, China; ${ }^{2}$ School of Economics and 403 Management, North China Electric Power University, Beijing 102206, China.

\section{Reference}

406 1. C.O.Okoye, O.Solyal1 (2017) Optimal sizing of stand-alone photovoltaic systems in residential 407 buildings. Energy 126:573-584

408 2. A. Maleki, F. Pourfayaz, H. Hafeznia, et al (2017) A novel framework for optimal photovoltaic 409 size and location in remote areas using a hybrid method: a case study of eastern Iran. Energy 410 Convers Manage 153:129-143

411 3. T. Khatib, A. Mohamed, K. Sopian, et al (2015) Optimal sizing of hybrid pv/wind systems for malaysia using loss of load probability. Energy Sources Part A 37(7):687-695 
413 4. A.K. Aliyu, B. Modu (2018) A review of renewable energy development in Africa: a focus in 414 South Africa, Egypt and Nigeria. Renewable and Sustainable Energy Reviews 81:2502-2518

415 5. F. Gokgoz, M.T. Guvercin (2018) Energy security and renewable energy efficiency in EU. 416 Renewable and Sustainable Energy Reviews 96:226-239

417 6. A. Vinel, E. Mortaz (2019) Optimal pooling of renewable energy sources with a risk-averse 418 approach: Implications for US energy portfolio. Energy Policy 132: 928-939

419 7. J. Liu (2019) China's renewable energy law and policy: a critical review. Renewable and 420 Sustainable Energy Reviews 99:212-219

421 8. Y. He, Y. Xu, Y. Pang, H. Tian, et al (2016) A regulatory policy to promote renewable energy 422 consumption in China: review and future evolutionary path. Renewable Energy 89:695-705

423 9. D. Liu, M. Liu, E. Xu, et al (2018) Comprehensive effectiveness assessment of renewable energy 424 generation policy: a partial equilibrium analysis in China. Energy Policy 115:330-341

425 10. International Renewable Energy Agency (2019) Renewable Capacity Statistics 2019

426 11. National Energy Administration (2019) China Renewable Energy Development Report 2018

427 12. Q. Tan, S. Mei, Q. Ye, et al (2019) Optimization model of a combined wind-PV-thermal 428 dispatching system under carbon emissions trading in China. Journal of Cleaner Production $429 \quad 225: 391-404$

430 13. W.Y. Chen, H.L. Li, Z.X. Wu (2011) Western China energy development and West to east energy 431 transfer: application of the western China sustainable energy development model. Energy Policy 432 38(11):7106-7120

433 14. M. Zeng, H.L. Li, M.J. Ma, et al (2013) Review on transaction status and relevant policies of 434 southern route in China's West-East Power Transmission. Renewable Energy 60:454-461

435 15. C.Y. Hua, C.M. Wang, H. Li, et al (2019) Analysis of basic conditions of the power grid 436 interconnection among Xinjiang, Pakistan, and five Central Asian countries. Global Energy 437 Interconnection 2(1):54-63

438 16. National Energy Administration (2016) Notice on Establishing Monitoring and Early Warning 439 Mechanism to Promote Sustainable and Healthy Development of Wind Power Industry 440 17. National Energy Administration (2017) Notice on Establishing Market Environment Monitoring 441 and Evaluation Mechanism to Guide the Healthy and Orderly Development of Photovoltaic Industry 442 18. X.L. Zhao, S.W. Liu, F.G. Yan, et al (2017) Energy conservation, environmental and economic 443 value of the wind power priority dispatch in China Renewable Energy 111:666-675

444 19. N.E. Koltsaklis, A.S. Dagoumas (2018) State-of-the-art generation expansion planning: a review. 445 Applied Energy 230:563-589

446 20. N.E. Koltsaklis, A.S. Dagoumas, G.M. Kopanos, et al (2014) A spatial multi-period long-term 
energy planning model: a case study of the Greek power system. Applied Energy 115:456-482

448 21. N.E. Koltsaklis, M.C. Georgiadis (2015) A multi-period, multi-regional generation expansion 449 planning model incorporating unit commitment constraints. Applied Energy 158:310-331

450 22. A.S. Dagoumas, N.E. Koltsaklis (2019) Review of models for integrating renewable energy in 451 the generation expansion planning. Applied Energy 242:1573-1587

452 23. S.Y. Chen, P. Liu, Z. Li (2019) Multi-regional power generation expansion planning with air 453 pollutants emission constraints." Renewable and Sustainable Energy Reviews 112:382-394

454 24. H. Chen, B.J. Tang, H. Liao, et al (2016) A multi-period power generation planning model 455 incorporating the non-carbon external costs: a case study of China. Applied Energy 183:1333-1345 456 25. M.D. Rodgers, D.W. Coit, F.A. Felder, et al (2018) Generation expansion planning considering 457 health and societal damages-A simulation-based optimization approach. Energy 164:951-963

458 26. I. Khan (2019) Power generation expansion plan and sustainability in a developing country: A 459 multi-criteria decision analysis. Journal of Cleaner Production 220:707-720

460 27. R. Banos, F. Manzano-Agugliaro, F. Montoya, et al (2011) Optimization methods applied to 461 renewable and sustainable energy: a review. Renewable and Sustainable Energy Reviews 15:17534621766

463 28. S. Upadhyay, M.P. Sharma (2014) A review on configurations, control and sizing methodologies 464 of hybrid energy systems. Renewable and Sustainable Energy Reviews 38:47-63

465 29. P.D. Lund, J. Lindgren, J. Mikkola, et al (2015) Review of energy system flexibility measures 466 to enable high levels of variable renewable electricity. Renewable and Sustainable Energy Reviews $467 \quad 45: 785-807$

468 30. J. English, T. Niet, B. Lyseng, et al (2020) Flexibility requirements and electricity system 469 planning: Assessing inter-regional coordination with large penetrations of variable renewable $470 \quad$ supplies. Renewable Energy 145:2770-2782

471 31. R. Gómez-Calvet, J.M. Martínez-Duart, S. Serrano-Calle (2019) Current state and optimal 472 development of the renewable electricity generation mix in Spain. Renewable Energy 135:1108$473 \quad 1120$

474 32. B. Canizes, J. Soares, F. Lezama, et al (2019) Optimal expansion planning considering storage 475 investment and seasonal effect of demand and renewable generation. Renewable Energy 138:937$476 \quad 954$

477 33. D. Quiroga, E. Sauma, D. Pozo (2019) Power system expansion planning under global and local 478 emission mitigation policies. Applied Energy 239:1250-1264

479 34. S. Pineda, A. Bock (2016) Renewable-based generation expansion under a green certificate 480 market. Renewable Energy 91:53-63 
481 35.Z.G. Lu, J.T. Qi, B. Wen, et al (2016) A dynamic model for generation expansion planning based 482 on Conditional Value-at-Risk theory under Low-Carbon Economy. Electric Power Systems 483 Research 141:363-371

484 36. S. Li, D.W. Coit, F. Felder (2016) Stochastic optimization for electric power generation 485 expansion planning with discrete climate change scenarios. Electric Power Systems Research $486 \quad 140: 401-412$

487 37. S. Pereira, P. Ferreira, A.I.F. Vaz (2017) Generation expansion planning with high share of 488 renewables of variable output. Applied Energy 190:1275-1288 
Figures

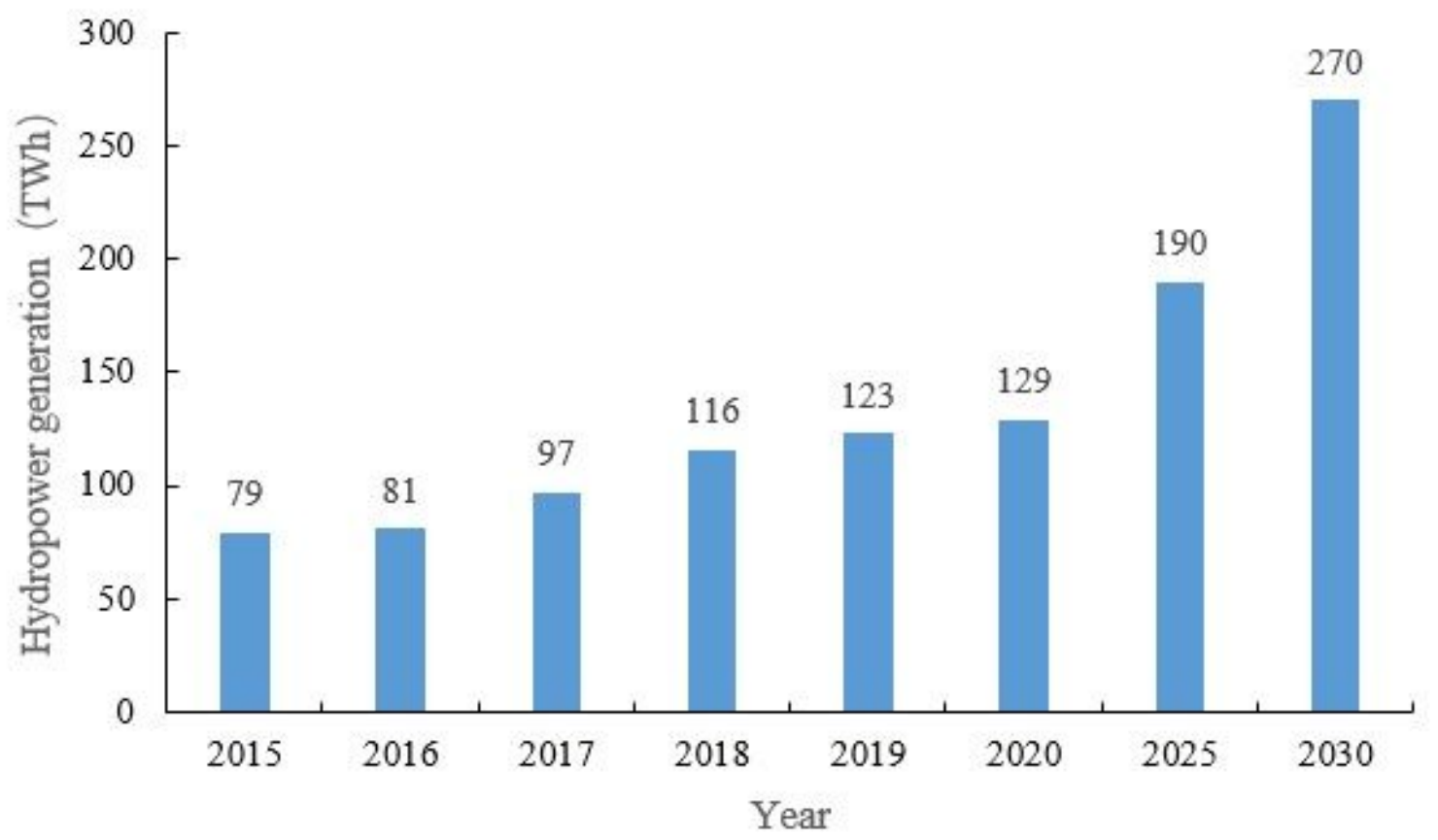

Figure 1

Self-use demand in Xinjiang during the planning period

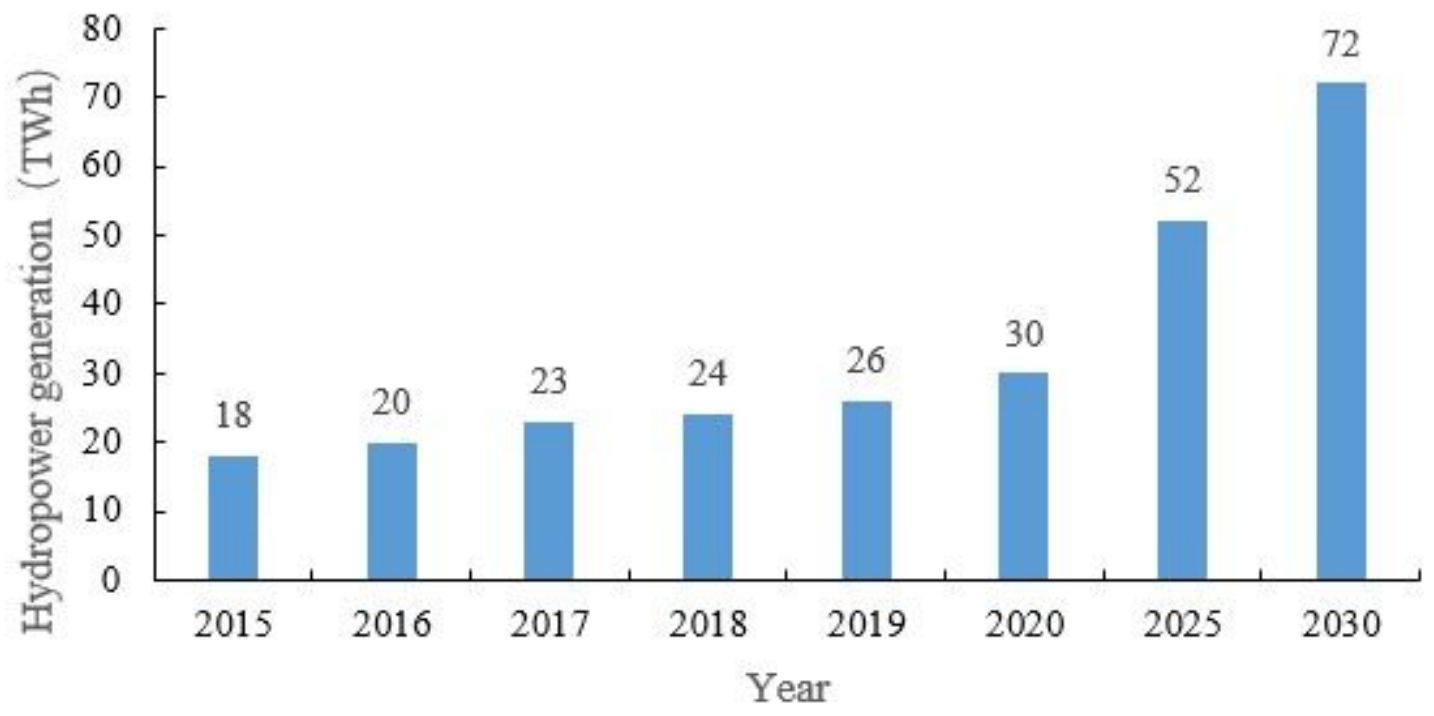

Figure 2

Hydropower generation amount during the planning period 


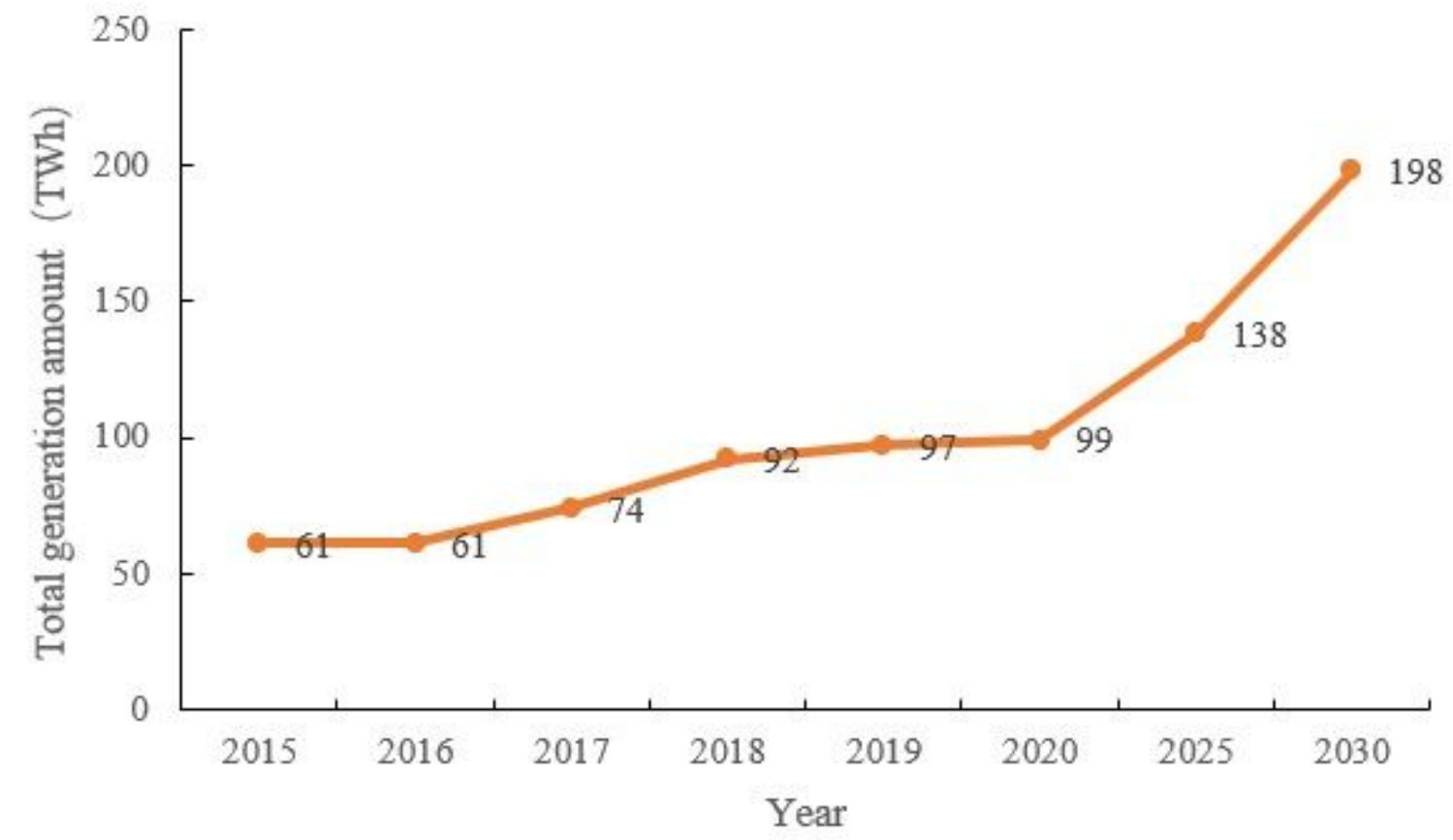

Figure 3

Total generation amount of three power resources

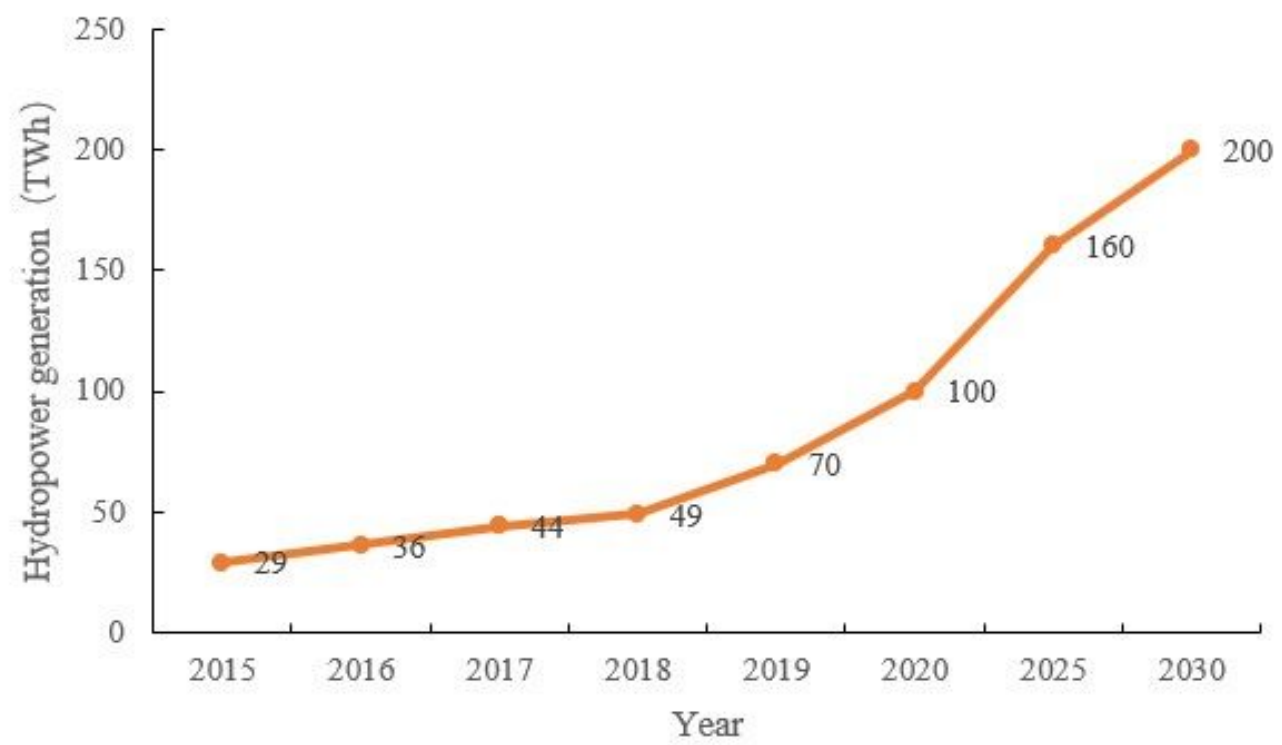

\section{Figure 4}

Total external power demand during the planning period 


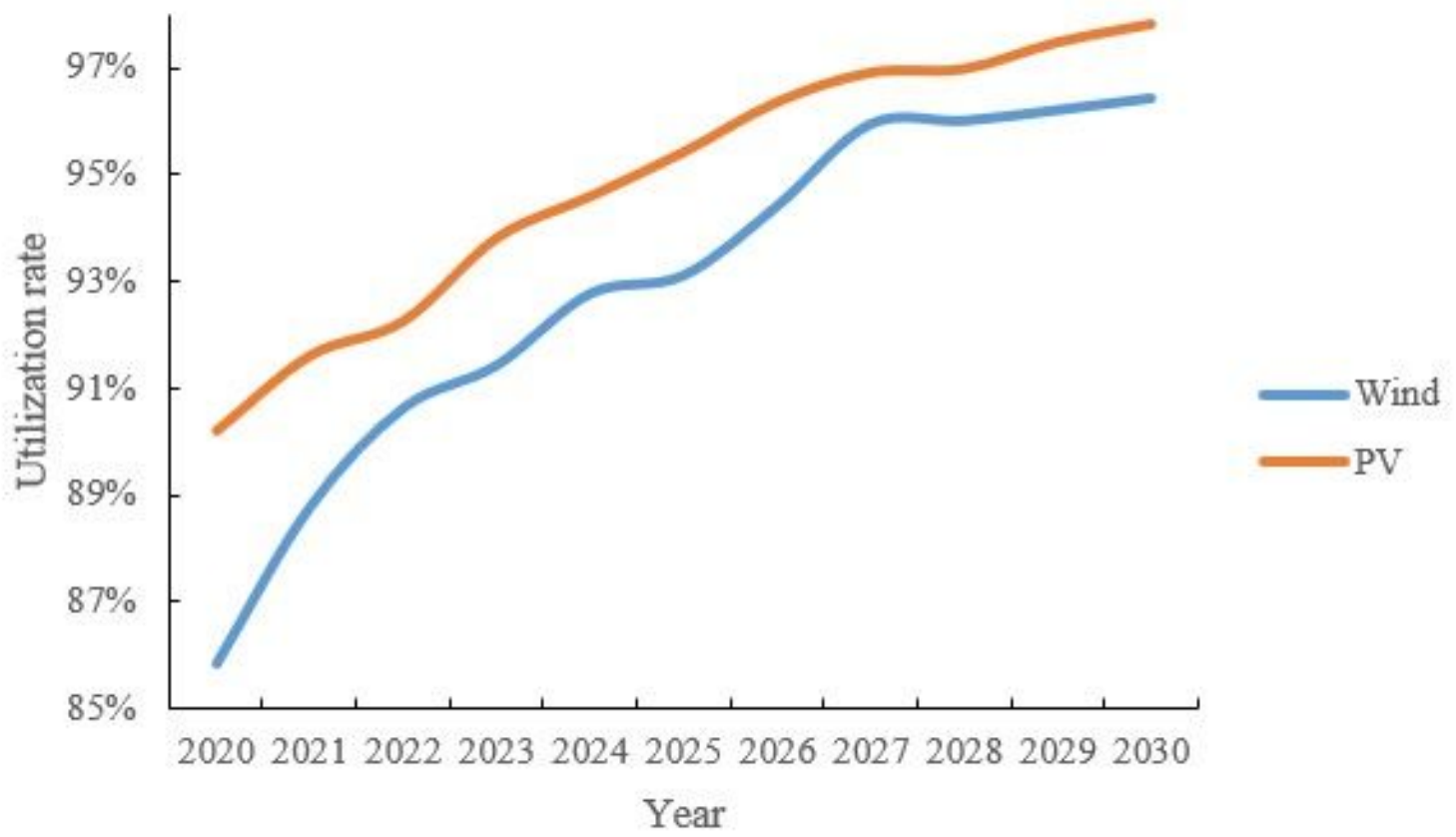

Figure 5

Utilization rate of renewable from 2020 to 2030

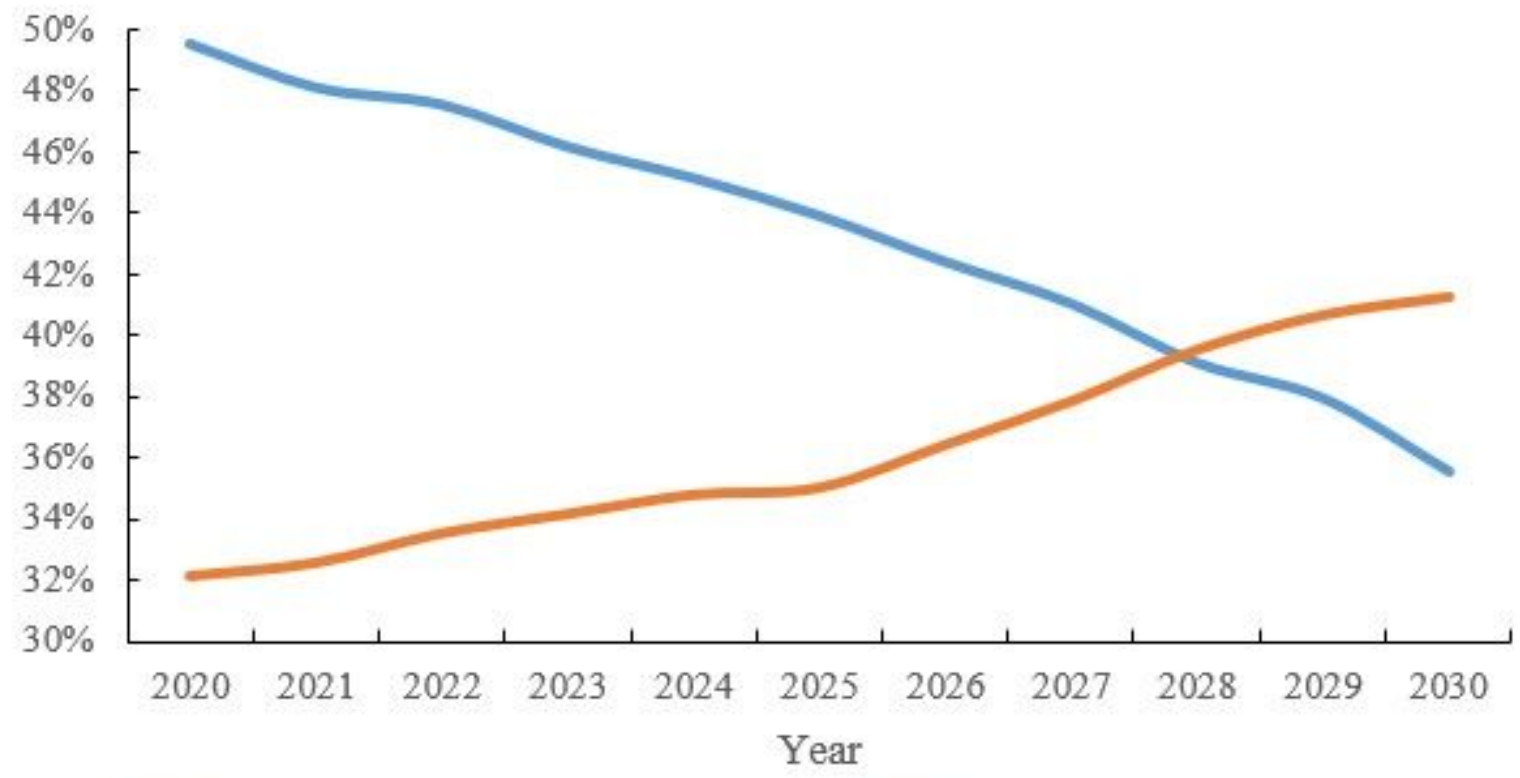

Proportion of thermal power installation $\longrightarrow$ Renewable energy penetration rate

\section{Figure 6}

The power structure of Xinjiang 


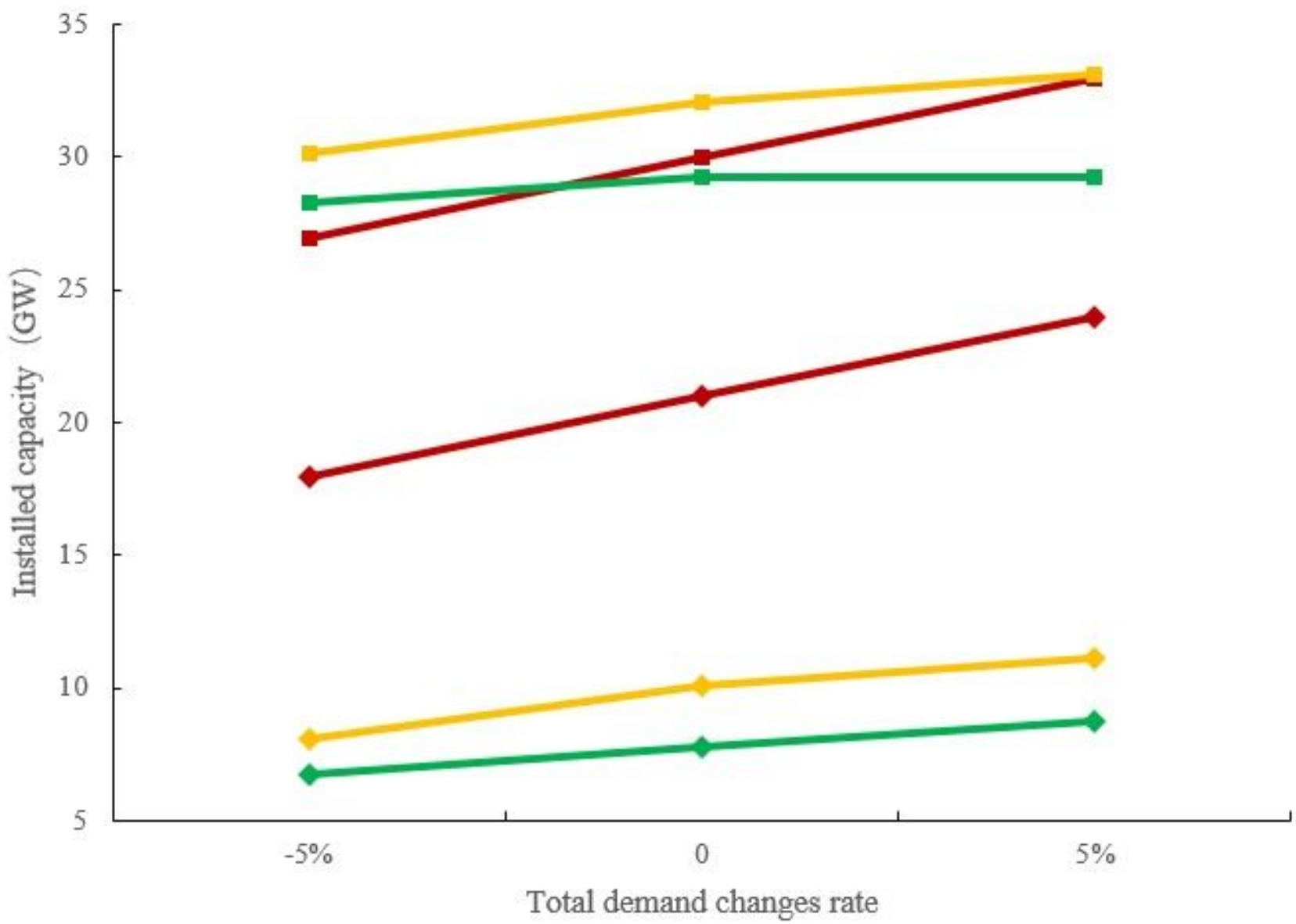

$\longrightarrow$ 2025thermal $\longrightarrow$ 2025wind $\longrightarrow$ 2025PV $\rightarrow$ 2030thermal -2030 wind $=2030 \mathrm{PV}$

\section{Figure 7}

Sensitivity analysis result of optimization model (excluded the external power plants) 